\title{
The Tractor and Semitrailer Routing Considering Carbon Dioxide Emissions
}

\author{
Hongqi Li, ${ }^{1}$ Yanran Li, ${ }^{1}$ Qiuhong Zhao, ${ }^{2}$ Yue Lu, ${ }^{1}$ and Qiang Song ${ }^{3}$ \\ ${ }^{1}$ School of Transportation Science and Engineering, Beihang University, No. 37 Xueyuan Road, Haidian District, Beijing 100191, China \\ ${ }^{2}$ School of Economics and Management, Beihang University, No. 37 Xueyuan Road, Haidian District, Beijing 100191, China \\ ${ }^{3}$ School of Humanities and Social Sciences, Beihang University, No. 37 Xueyuan Road, Haidian District, Beijing 100191, China \\ Correspondence should be addressed to Qiuhong Zhao; qhzhao@buaa.edu.cn
}

Received 5 July 2013; Revised 10 November 2013; Accepted 10 November 2013

Academic Editor: John Gunnar Carlsson

Copyright (c) 2013 Hongqi Li et al. This is an open access article distributed under the Creative Commons Attribution License, which permits unrestricted use, distribution, and reproduction in any medium, provided the original work is properly cited.

The incorporation of the minimization of carbon dioxide $\left(\mathrm{CO}_{2}\right)$ emissions in the VRP is important to logistics companies. The paper deals with the tractor and semitrailer routing problem with full truckload between any two depots of the network; an integer programming model with the objective of minimizing $\mathrm{CO}_{2}$ emissions per ton-kilometer is proposed. A two-stage approach with the same core steps of the simulated annealing (SA) in both stages is designed. The number of tractors is provided in the first stage and the $\mathrm{CO}_{2}$ emissions per ton-kilometer are then optimized in the second stage. Computational experiments on small-scale randomly generated instances supported the feasibility and validity of the heuristic algorithm. To a practical-scale problem, the SA algorithm can provide advice on the number of tractors, the routes, and the location of the central depot to realize $\mathrm{CO}_{2}$ emissions decrease.

\section{Introduction}

Recent studies in freight transportation have focused not only on cost minimization or profit maximization for a freight company but also on carbon reduction [1]. Carbon dioxide $\left(\mathrm{CO}_{2}\right)$ is emitted during the combustion of fossil fuels to drive vehicles. The efficient use of trucks and road networks becomes more and more important to enhance the corporate social responsibility for companies. Optimized vehicle routing can reduce the number of trucks and utilize better the network by reducing vehicle movements. The optimization problem has been extensively studied in the literature, known as the vehicle routing problem (VRP).

The incorporation of the minimization of fuel consumption and $\mathrm{CO}_{2}$ emissions in the VRP is a relatively recent topic addressed in the research work. VRP-related research that aims to minimize total fuel consumption is rather rare [2]. Kara et al. [3] define an energy-minimizing VRP that minimizes the weighted load instead of a distance based objective function. Kuo [2] calculated total fuel consumption for the time-dependent VRP. Lin and $\mathrm{Ng}$ [1] formulated a two-stage stochastic program to minimize the emission of the carriers to see the effects of backhaul collaboration. Xiao et al. [4] extended the capacitated VRP taking into account travel distance and load impacts on fuel costs. Kwon et al. [5] used a mixed integer programming model to investigate the heterogeneous fixed fleet VRP with carbon emission.

From the experimental results of Pradenas et al. [6], the type of vehicles and the use rate of vehicles are important factors affecting $\mathrm{CO}_{2}$ emissions of the vehicle routing. We distinguish the VRP and its extensions by considering both vehicle types and service segment types. (i) The constitution mode of the autonomous part and the nonautonomous part can classify vehicles into two types [7]: trucks and combination vehicles. In some extensions of the VRP, the combination vehicles and especially the use of trailers are considered. (ii) The road freight industry has basically two types of service segments: full truckload (TL) shipping and less-than-truckload (LTL) shipping. TL is more suitable for customers with large shipment sizes that require individual 
tailored services such as direct transportation between two points; LTL is more appropriate for clients that have to share the carrier's transportation resources with other customers [8]. Most VRP research concentrated on the optimization of delivery or/and pickup of LTL service.

Logistics companies use various types of vehicles and operate from more than one distribution center. Shipments occur between depots and the pickup/delivery locations of orders and between depots. In multilevel freight distribution systems (e.g., city logistics, multimodal freight transportation systems, parcels, or public postal services) in which freight arrives at a depot and is transported further to another depot by large vehicles and the freight is then brought to the final customers by small vehicles, both TL and LTL appear. The problem how to efficiently route vehicles operating at both levels is known in the literature as the two-echelon vehicle routing problem (2E-VRP) [9], the generalized vehicle routing problem (GVRP) [10], or the single-sourcing twoechelon capacitated location-routing problem (2E-CLRP) [11].

Compared with most VRP research employing trucks to serve the delivery or/and pickup of LTL, we study a variant of the combination-vehicle routing problem where tractor-semitrailer combinations are utilized. A tractor can pull multiple and independent trailers. The tractor cannot load goods and is only used for pulling the trailers. Since the time to attach/detach a semitrailer to a tractor at locations is usually considerably less than the time to load/unload all cargoes in a semitrailer, the tractor has a high use rate. We call this variant of the VRP as the tractor and semitrailer routing problem (TSRP). The tractor and semitrailer transportation is regarded to be more energy-efficient than single-unit truck transportation [12]. As Van Ierland et al. [13] stated, the $\mathrm{CO}_{2}$ emission factor, which is defined as $\mathrm{CO}_{2}$ emissions per tonkilometer (unit: $\mathrm{g} \mathrm{CO}_{2} / \mathrm{t}-\mathrm{km}$ ), is a typical index to describe the $\mathrm{CO}_{2}$ emission effects of the road freight transportation. Differing from other pieces of literature, we aim to minimize $\mathrm{CO}_{2}$ emissions per ton-kilometer of the TSRP.

We propose the TSRP on a loaded semitrailer flow network. The loaded semitrailers are assumed to be TL. There are two types of terminals on the network: one central depot and a number of satellite depots. At the beginning, all tractors locate in the central depot, while the satellite depots have loaded semitrailers waiting for sending. All tractors or vehicles (a vehicle is one tractor pulling one semitrailer) originate and terminate at the central depot. A homogeneous fleet composed of tractors and semitrailers serves the loaded semitrailer flow demand among depots. A tractor can pull one loaded semitrailer and can also run alone. The objective of the TSRP is to determine the number of tractors and the route of each tractor so as to minimize $\mathrm{CO}_{2}$ emissions per ton-kilometer.

Our interest in the TSRP arises from the full truckload transporting of multilevel freight distribution systems. Our aim is to develop a solving method for the TSRP and to show the effect of $\mathrm{CO}_{2}$ emission mitigation. The paper is organized as follows. The next section introduces the relevant literature. A mathematical model for the TSRP is developed in Section 3. Section 4 proposes the heuristic algorithm for solving the TSRP. Computational experiments are described in Section 5. Finally, conclusions and future work are given in Section 6.

\section{The Literature Review}

The introduction reviewed briefly the limited literature directly targeting the incorporation of $\mathrm{CO}_{2}$ emissions minimization in the VRP. We turn to a brief overview of contributions to the combination-vehicle routing problem the TSRP concerns.

Research on the VRP to date has considered especially trucks and truck and full trailer combinations. The truck and trailer routing problem (TTRP) has been brought forward for decades. In the TTRP, a heterogeneous fleet composed of trucks and trailers serves a set of customers. Both the truck and the trailer have hauling capacity and goods can be transferred between the truck and the trailer en-route in the parking places of the trailer. Each customer has a certain demand, and the capacities of the trucks and trailers are determinate. Some customers must be served only by a truck, while other customers can be served either by a truck or by a combination vehicle. The objective of the TTRP is to find a set of routes with minimum total distance or cost so that each customer is visited. Interested readers are referred to Villegas et al. [14] in order to get an overview of recently related publications of the TTRP.

Semet and Taillard [15] and Caramia and Guerriero [16] provided some real-world TTRP applications. Gerdessen [17] extended the VRP to the VRP with trailers and investigated the optimal deployment of a fleet of truck-trailer combinations. Chao [18] distinguished three types of routes in a TTRP solution. Subsequently, Scheuerer [19], Tan et al. [20], Lin et al. [21], and Villegas et al. [22] solved the TTRP by various heuristics. On the extensions of the TTRP, Villegas et al. [23] proposed two metaheuristics to solve the single truck and trailer routing problem with satellite depots (STTRPSD). Considering the number of available trucks and trailers being limited in the TTRP, Lin et al. [24] relaxed the fleet size constraint and developed a SA heuristic for solving the relaxed truck and trailer routing problem (RTTRP). Lin et al. [25] proposed a SA heuristic for solving the truck and trailer routing problem with time windows (TTRPTW). Recently, Derigs et al. [26] combined local search and large neighborhood search metaheuristic to solve the TTRP with/without load transfer and the TTRP with/without time windows. Villegas et al. [14] presented a two-phase matheuristic to the TTRP. A pool of routes with the local optima was obtained by a hybrid GRASP $\times$ ILS metaheuristic, and these routes become columns in a set-partitioning problem solved with a mixed integer programming optimizer.

In the TTRP, each trailer can be pulled by a unique associated truck, and only this truck is permitted to transfer the load into the trailer. The amount of trucks is generally more than that of trailers. Drexl [7] described the VRP with trailers and transshipments (VRPTT) in which there is no fixed trucktrailer assignment. The TTRP is evidently a special case of the VRPTT. Besides, Pureza et al. [27] addressed the VRP 
with time windows and multiple deliverymen (VRPTWMD) that allows a number of deliverymen to be assigned to each route. Two solution approaches based on tabu search and ant colony optimization were proposed. The impact of the use of extra deliverymen in route planning was assessed by means of computational experiments. If regarding deliverymen as trucks, the VRPTWMD becomes the TTRP when there is only one deliveryman.

There are several variants of the VRP which consider tractor and semitrailer combinations. These variants include the rollon-rolloff vehicle routing problem (RRVRP) and others. In the literature, the RRVRP arises when tractors move trailers between locations generating a high volume of waste like construction sites and disposal facilities. In the basic RRVRP, there is a single depot where all tractors are located at the beginning and there is a single disposal facility where full trailers get dumped and empty trailers can be put on or pulled from inventory. At the end of the day, all tractors return to the depot while trailers may remain at customer locations or the disposal facility. The problem is to assign trips to tractors and to find routes for the tractors which do not exceed a given maximal duration and which altogether minimize the nonproductive deadhead time of tractors between trips as well as the number of tractors used.

Bodin et al. [28] studied the RRVRP with a depot and a disposal site and classified customer demands of four trip types. Heuristic methods were proposed to solve some benchmark problems on the RRVRP. Wy and Kim [29] proposed a hybrid metaheuristic approach that consists of a large neighborhood search and various improvement methods to solve the RRVRP. The benchmark data of Bodin et al. [28] were used to test the effectiveness of the proposed method. Derigs et al. [30] solved the RRVRP by combining local search and large neighborhood search controlled by two relatively simple and parameter-free/-poor metaheuristic control procedures. Wy et al. [31] introduced the RRVRP with time windows (RRVRPTW). The objective of the RRVRPTW is to minimize the number of required tractors and their total route time. A LNS based iterative heuristic approach consisting of a construction algorithm and several improvement algorithms was proposed. Baldacci et al. [32] modeled the multiple disposal facilities and multiple inventory locations RRVRP (M-RRVRP) as a time constrained VRP on a multigraph.

There are other variants concerning the tractor and semitrailer combination routing problem. Hall and Sabnani [33] studied routes that consisted of two or more segments and two or more stops in the route for a tractor. Control rules based on predicted route productivity were developed to determine when to release a tractor. Francis et al. [34] solved the multiresource routing problem (MRRP) with flexible tasks. Two resources (tractors and trailers) performed tasks to transport loaded and empty equipment. Cheng et al. [35] proposed a model for a steel plant to find the tractor and semitrailer running routes to minimize transport distance. Derigs et al. [36] presented two approaches to solve the VRP with multiple uses of tractors and trailers. With an assumption of exactly one semitrailer in each depot and an explanation on the relationship between the assumption and any number of vehicles in a depot, Li et al. [37] studied the tractor and semitrailer routing problem on a unit-flow network (TSRP-UF), and a heuristic algorithm was used to decide the number of tractors and the route of each tractor.

Among all the work we have reviewed, little work has been done on the problem we have described earlier, in which the tractor and semitrailer combination vehicles are used for the TL of multilevel freight distribution systems. The objective of our problem is to provide the number of tractors used and reduce the disparity of routes of the tractors to minimize $\mathrm{CO}_{2}$ emissions per ton-kilometer. We are going to discuss this problem in detail in the next section.

\section{Model Formulation}

The underlying assumptions of the TSRP model include the following:

(i) All loaded semitrailer flow demands are known in advance. Empty semitrailer exchanges are ignored.

(ii) Loaded semitrailer flow demand can originate between any two depots.

(iii) A route must not exceed a given distance span. In order to reduce the disparity of routes and to balance tractors workload, a route must exceed a given minimization-distance.

(iv) Routes start and end at the central depot. If a satellite depot is already present in a route, it cannot be reinserted in the same route.

(v) All tractors are assigned to the central depot where they must return to after each route. Each tractor leaves from and returns to the depot once or more.

(vi) The TSRP is a homogeneous vehicle routing.

The TSRP can be formulated as follows.

Let $G=(V, A)$ be a directed graph where $V=\{0,1,2, \ldots$, $n\}$ is the vertex set and $A=\{(i, j) \mid i, j \in V, i \neq j\}$ the arc set. Vertex $0\left(v_{0}\right)$ is the central depot and other vertices $\left(v_{i}\right)$ in $V$ (i.e., $V \backslash\{0\}$ ) correspond to satellite depots. Denote the distance between $v_{i}$ and $v_{j}$ as $d_{i j}$ and the running time from $v_{i}$ to $v_{j}$ as $t_{i j}$. Loaded semitrailer flows between any two depots are $R$ :

$$
R=\left[\begin{array}{ccccc}
0 & r_{01} & r_{02} & \cdots & r_{0 n} \\
r_{10} & 0 & r_{12} & \cdots & r_{1 n} \\
r_{20} & r_{21} & 0 & \cdots & r_{2 n} \\
\vdots & \vdots & \vdots & \vdots & \vdots \\
r_{n 0} & r_{n 1} & \cdots & r_{n, n-1} & 0
\end{array}\right],
$$

where $r_{i j}$ denotes that there are $r_{i j}$ loaded semitrailer s needed to be transported from $v_{i}$ to $v_{j}$.

$C_{i j k}^{t}$ is the fuel consumption of the $k$ th tractor running from $v_{i}$ to $v_{j}$, and $C_{i j k}^{l}$ is the fuel consumption of the $k$ th combination vehicle running from $v_{i}$ to $v_{j}$. vel ${ }^{t}$ is the average velocity of the $k$ th tractor running alone from $v_{i}$ to $v_{j}$. vell is the average velocity of the $k$ th combination vehicle running from $v_{i}$ to $v_{j}$. Suppose that vel ${ }^{t}=\operatorname{vel}^{l}=$ vel; then $d_{i j}=$ 
vel $\cdot t_{i j}$; the total number of tractors used is $H$; the minimum distance and the maximum distance of a route are $D_{1}$ and $D_{2}$, respectively.

$X_{i j k}^{t}$ and $X_{i j k}^{l}$ are the decision variables. If the $k$ th tractor runs from $v_{i}$ to $v_{j}$ for $\alpha$ times, $X_{i j k}^{t}=\alpha$; if the $k$ th combination vehicle (i.e., the $k$ th tractor pulling one loaded semitrailer) runs from $v_{i}$ to $v_{j}$ for $\beta$ times, $X_{i j k}^{l}=\beta$.

The objective function is

$$
\operatorname{Min} \frac{\gamma \cdot\left(\sum_{i} \sum_{j} \sum_{k} C_{i j k}^{t} X_{i j k}^{t}+\sum_{i} \sum_{j} \sum_{k} C_{i j k}^{l} X_{i j k}^{l}\right)}{W \cdot \sum_{k} \sum_{i} \sum_{j} X_{i j k}^{l} \cdot d_{i j}} .
$$

The constraints are

$$
\begin{gathered}
\sum_{k} X_{i j k}^{l}=r_{i j}, \\
\sum_{i} X_{j i k}^{t}+\sum_{i} X_{j i k}^{l} \geq 1, \\
\sum_{i} X_{i j k}^{t}+\sum_{i} X_{i j k}^{l} \geq 1, \\
\sum_{i} X_{j i k}^{t}+\sum_{i} X_{j i k}^{l}=\sum_{i} X_{i j k}^{t}+\sum_{i} X_{i j k}^{l}, \\
\sum_{i} \sum_{j}\left(d_{i j} \cdot X_{i j k}^{t}+d_{i j} \cdot X_{i j k}^{l}\right) \geq D_{1}, \\
\sum_{i} \sum_{j}\left(d_{i j} \cdot X_{i j k}^{t}+d_{i j} \cdot X_{i j k}^{l}\right) \leq D_{2} .
\end{gathered}
$$

$X_{i j k}^{t}$ and $X_{i j k}^{l}$ are integers; $i, j=0,1,2, \ldots, n ; i \neq j ; k$ is an integer and the maximum $k$ is the total of tractors used $(H)$; $H \geq\left(\sum_{i} \sum_{j} d_{i j} \cdot r_{i j}\right) / D_{2}$.

The objective function is the $\mathrm{CO}_{2}$ emissions per tonkilometer where $\gamma$ is the emission coefficient and $W$ the freight weight on a loaded semitrailer. Constraints (3) guarantee that the freight flow demand is satisfied. Constraints (4), (5), and (6) guarantee the assumption ( $v$ ), and constraints (6) also guarantee vehicle balance of satellite depots. Constraints (7) and (8) are the restriction of balancing the route lengths.

Generally, efficient exact algorithms to solve the model we presented here for realistic problem sizes do not exist. Thus, such model can only be solved by heuristics to attain suboptimal solutions of a priori unknown quality.

\section{A Two-Stage Heuristic Algorithm Based on the SA}

Three types of algorithms are used to solve the VRP [38]. The first type consists of exact algorithms that are timeconsuming. The second type consists of classical heuristics such as greedy, local search, and relaxation based. The third type consists of heuristics that are based on some metaheuristic rules. Such metaheuristics or framework for building heuristics are the SA, tabu search, genetic algorithms, variable neighborhood search, and so forth. The high computational cost of exact methods and their poor performance in large problems have involved that the current research concentrates on stochastic algorithms that are capable of producing feasible but not necessarily optimal solutions in limited time [39].

The SA algorithm is one of the commonly used metaheuristics and has been successfully applied to solve several types of the VRP. Motivated by the success of the SA for the TTRP (e.g., [24, 25]), we have therefore opted a heuristic algorithm based on the SA to solve the TSRP.

The SA uses a stochastic approach to search for and move to neighborhood solutions. If a better neighborhood solution is identified in the search starting from the current solution, then the move will be accepted and the current solution will be replaced by the better neighborhood solution. The search for a better neighborhood solution then continues. Besides, the SA will accept the moving to a worse neighborhood solution with a certain probability so as to escape from a local optimum. The accepted probability is based on two parameters, the temperature which gradually reduces and the objective function difference between the two solutions. In the beginning of the search, the accepted probability of the move is high. When nearing the end of the search process the accepted probability of the move is small. The initial temperature, the cooling function, and the final temperature affect the results of the SA.

4.1. Neighborhood and Initial Solution. Local search plays a very important role in the design of metaheuristics for the VRP [40]. A local search operator iteratively improves a solution by exploring its neighborhood. The TSRP model in Section 3 suggests that the route is made up of sequential arcs. We regard constraints (7) and (8) as the most important factors to decide the solution's neighborhood.

Regulations related to long-distance transportation impose complex rules for driving time and driver breaks. Combining the VRP with break scheduling leads to complicated route feasibility checks. The distance span (or time-span when the velocity is constant) constraint is usually an important consideration in the VRP. Almoustafa et al. [38] investigated distance constrained VRP (DVRP) where the total travelled distance by each vehicle in the solution is less than or equal to the maximum possible travelled distance. Letchford and Salazar-González [41] took DVRP as a special case of VRP with time windows constraints. Through the minimization-distance and the maximization-distance included in constraints, the workload of divers and tractors is balanced.

The distance span constraints decide that the routes include finite inserted satellite depots. We can enumerate the number of satellite depots in a route to search entirely to find all routes that satisfy distance span constraints. When the routes include at least 1 and at most $f_{k^{\prime}}$ satellite depots, there are $O\left(n^{f_{k^{\prime}}}\right)$ potential routes for selection. The neighborhood is made up of routes.

Referring to the traditional destroy and repair framework, we take a whole route as the operator unit. There are three types of operators. (i) A route is removed from the current solution by a destroy operator. (ii) A route is removed from the current solution by a destroy operator and another route is 


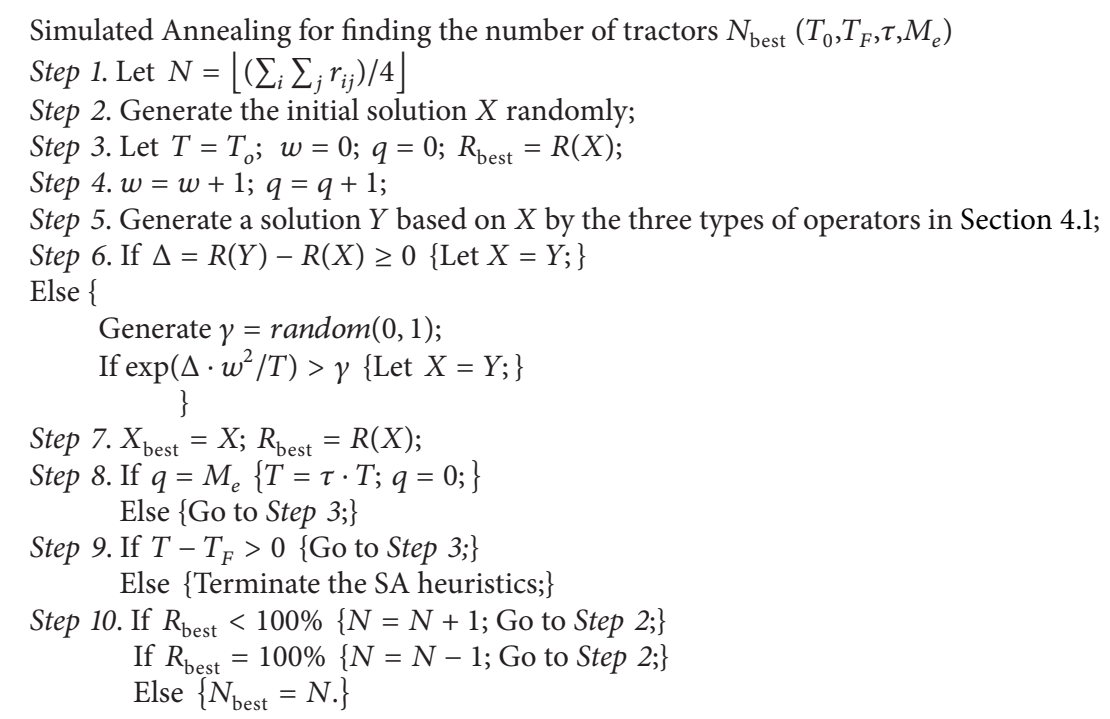

Pseudocode 1: Pseudocode of the proposed SA heuristics for finding the number of tractors.

reinserted by a repair operator. The removed route is recorded by the neighborhood and is still a candidate route of the repair operator. (iii) A route may clone itself several times, and the times are decided by the maximum demand of satellite depots included in the route. The clone operator is a special type of repair operators.

For the generation of the initial solution, our computational tests showed a similar conclusion as that of Coelho et al. [42]. The initial solution does not have a significant impact on the overall solution cost or the running time. We therefore generate randomly the initial solution.

4.2. The SA Heuristics. Research dealing with the VRP is generally based on a two-stage approach where the number of routes is minimized in the first stage and the other objective is then optimized in the second one. Minimizing the number of vehicles is often considered the primary objective. Meanwhile, several practical situations directly considered the other objective (e.g., total transporting distance) as the primary objective [43]. We deal with the TSRP based on SA heuristics in the paper to find firstly the number of tractors used and then the routes so as to minimize $\mathrm{CO}_{2}$ emissions per ton-kilometer.

The number of tractors (or the number of routes in the solution) is an essential parameter at the beginning of the SA heuristics. It is certain that a tractor pulls more than one independent semitrailer on the route. Denoting the average number of transported loaded semitrailer s on a route as $\xi$, then $\left(\sum_{i} \sum_{j} r_{i j}\right) / \xi$ is an important bound of the number of tractors needed. The computational tests showed that it is feasible for $\xi=4$. The SA procedure is started by selecting randomly $N=\left\lfloor\left(\sum_{i} \sum_{j} r_{i j}\right) / 4\right\rfloor$ routes as the initial solution where $\lfloor\cdot\rfloor$ denotes the largest integer which is smaller than or equal to the enclosed number.
In the beginning of the SA heuristics, the current temperature $T$ is set to be the same as $T_{0}$. Then an initial solution $X$ is generated randomly from the neighborhood described in Section 4.1. The current best solution and the best percentage of satisfied freight demand obtained so far are set to be $X$ and $R(X)$, respectively. At each iteration, the next solution $Y$ is generated from the neighborhood and its percentage of satisfied freight demand is evaluated. Let $\Delta$ denote the difference between $R(X)$ and $R(Y)$; that is, $\Delta=R(Y)-R(X)$. The probability of replacing $X$ with $Y$, given that $\Delta<0$, is $\exp \left(\Delta \cdot w^{2} / T\right)>\gamma$ where $w$ is an integer. This is accomplished by generating a random number $\gamma \in[0,1]$ and replacing solution $X$ with $Y$ if $\gamma<\exp \left(\Delta \cdot w^{2} / T\right)$. Meanwhile, if $\Delta \geq$ 0 , the probability of replacing $X$ with $Y$ is $1 . M_{e}$ iterations are run during the course of temperature $T$ decreasing to temperature $\tau T$ where $0<\tau<1$. The algorithm is terminated when the current temperature $T$ is lower than $T_{F}$. Following the termination of the SA procedure, the number of tractors $N_{0}$ is adjusted according to the percentage of satisfied freight demand of the solution. The SA approach to find the number of tractors is summarized in Pseudocode 1.

In the second phase, successive $\mathrm{CO}_{2}$ emissions per tonkilometer are minimized for the current number of tractors until a predefined stopping criterion is met (e.g., the $\mathrm{CO}_{2}$ emissions per ton-kilometer stop decrease or the number of iterations). The core steps (steps $2 \sim 8$ in Pseudocode 1) of the SA heuristics of both phases are the same. Let $C_{0}$ the $\mathrm{CO}_{2}$ emissions per ton-kilometer attained by the SA heuristic that has found the number of tractors. Let $\mathrm{C}(X)$ the $\mathrm{CO}_{2}$ emissions per ton-kilometer of solution $X$. The SA heuristic for routes is summarized in Pseudocode 2.

\section{Computational Study}

Since we are not aware of any prior test instance for the TSRP minimizing $\mathrm{CO}_{2}$ emissions per ton-kilometer, the proposed 


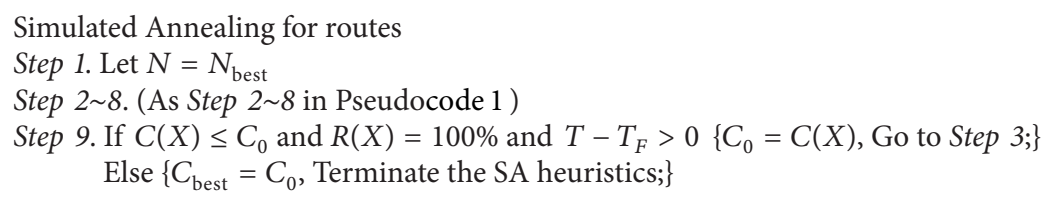

Pseudocode 2: Pseudocode of the proposed SA heuristics for routes.

model and algorithm were tested on a range of randomly generated small-scale instances and a realistic instance. The SA heuristic algorithm was coded in MATLAB and run on a computer with an AMD Athlon (tm) X2 Dual-Core QL-65 running at $2.10 \mathrm{GHz}$ under Windows 7 ultimate (32 bits) with $2 \mathrm{~GB}$ of RAM. Our computational experiments were carried out in two parts. First, we calibrated the solution methods on a set of small-scale instances as explained in Section 5.1. Second, we run the SA heuristics on a realistic instance as explained in Section 5.2.

5.1. Small-Scale Instances. The lack of publicly available test instances for the considered problem prevented from comparing our results to similar results from the literature. Therefore, our test examples were randomly generated, in such a way that the number of satellite depots $n$ was varied from 4 to 7 with increment 1 . Moreover, for each value of $n, 10$ instances were produced with different flow network characteristics (depot locations, distances, and loaded semitrailer flows) which are summarized in Table 1. Columns 19 indicate the test problem, the rectangle region, the total number of loaded semitrailer, the average loaded semitrailer number of all satellite facilities, the variance of loaded semitrailer number of all satellite facilities, the minimum distance between central depot and satellite facility, the maximum distance between central depot and satellite facility, the average distance between any two terminals, and the variance of distances between any two terminals, respectively.

The tractor-semitrailer combination, which can load maximally 30 tons and satisfies the fuel-efficiency requirements of "Regulation of Supervising Vehicle Fuel Consumption" (no. 11/2009 Decree of Ministry of Transport of the People's Republic of China (MOTPRC)), is used in the small-scale instances. The type codes of the selected combinations are "CQ4254HTVG324V" and "ND4251B32J7." When the velocity is $50 \mathrm{~km} / \mathrm{h}$, the fuel consumption is 18 litres diesels per 100 kilometers for tractor running alone and 32 litres diesels per 100 kilometers for combination running. Supposing that the loading factor of loaded semitrailer is $50 \%$, the distance span is from $500 \mathrm{~km}$ to $700 \mathrm{~km}$.

The integer programming model presented in Section 3 has been implemented and solved using CPLEX 12.4. The computational results are presented in Table 2.

As shown in Table 2, we can find that the solution $\mathrm{CO}_{2}$ emissions per ton-kilometer obtained by the proposed SA heuristics are close to the integer programming model solution. For some instances, such as RAND5-7, RAND58, RAND6-7, RAND6-9, and RAND7-8, the gaps between the heuristic solution and the integer programming model solution are less than $1 \%$. For all 40 test instances, the largest percentage gap is $17.9 \%$, and the average percentage gap is $7.0 \%$. Out of 40 test instances, the gap is less than $10 \%$ in 22 cases. A phenomenon worth to notice is that the location of a central depot likely affects the percentage gap. Instances with percentage gaps of over $10 \%$ generally have their central depots located alongside the boundary of the regions.

Although we can solve the TSRP using the sequential formulation, it is still computationally challenging. It can be observed that, even for a 10-node problem, CPLEX MIP solver failed to prove the near optimality of the solution, due to being time-consuming or the insufficient memory resources. Thus, a heuristic algorithm is essential for the problem to improve the computational effectiveness.

5.2. A Realistic Instance. The main purpose of the realistic instance study is to evaluate the applicability of the developed SA heuristics for realistic-size problems. A LTL trucking company in Shandong province of China, simply named SDEXP, is the object of our computational study. SDEXP comprises 17 depots distributed in 17 cities in Shandong province. We abbreviate the 17 city names to JNA (Jinan), DZH (Dezhou), LCH (Liaocheng), TA (Taian), LW (Laiwu), HZ (Heze), JNI (Jining), ZZH (Zaozhuang), LY (Linyi), RZH (Rizhao), QD (Qingdao), YT (Yantai), WH (Weihai), WF (Weifang), ZB (Zibo), BZH (Binzhou), and DY (Dongying), respectively. SDEXP employed hundreds of single-unit trucks to transport cargoes before 2007 and had a road freight market share of about $1.2 \%$ in Shandong province. Along with the policy on encouraging and popularizing tractor and semitrailer combinations in China, SDEXP plans to substitute tractor and semitrailer combinations for single-unit trucks.

We abstract the transportation network of SDEXP on a graph, where the nodes denote the cities. The arcs denote highway infrastructure connecting every two cities. SDEXP plans to rebuild a central depot by selecting one of the depots located in the following 6 cities: JNA, QD, ZB, WF, TA, and LW. Suppose that any one of the 6 city depots can be regarded as a central depot and all other city nodes as satellite depots. Table 3 gives the distances between every two cities. SDEXP's expected freight flows between any two cities per day are given in Table 4.

The tractor-semitrailer combination adopted in the small-scale instances is used in the realistic instance. The loading factor of loaded semitrailer is $50 \%$; the velocity is $80 \mathrm{~km} / \mathrm{h}$. The distance span is affected by drivers' on-duty 
TABLE 1: Basic characteristics of the 40 test problems.

\begin{tabular}{|c|c|c|c|c|c|c|c|c|}
\hline \multirow[t]{2}{*}{ Problem } & \multirow[t]{2}{*}{ Region $(\mathrm{km} \times \mathrm{km})$} & \multicolumn{3}{|c|}{ Freight flow demand (loaded-semitrailer) } & \multicolumn{2}{|c|}{$\begin{array}{l}\text { Distance between central } \\
\text { depot and satellite depot }\end{array}$} & \multicolumn{2}{|c|}{$\begin{array}{l}\text { Distance between any two } \\
\text { depots }\end{array}$} \\
\hline & & Total & Average & Variance & Min. & Max. & Average & Variance \\
\hline RAND5-1 & $200 \times 150$ & 49 & 2.5 & 1.0 & 50 & 200 & 126.7 & 2712.6 \\
\hline RAND5-2 & $200 \times 200$ & 51 & 2.6 & 1.0 & 50 & 200 & 133.3 & 2298.9 \\
\hline RAND5-3 & $250 \times 200$ & 60 & 2.4 & 1.1 & 50 & 200 & 163.3 & 4988.5 \\
\hline RAND5-4 & $200 \times 200$ & 58 & 2.9 & 0.8 & 50 & 200 & 133.3 & 2298.9 \\
\hline RAND5-5 & $200 \times 250$ & 46 & 2.3 & 1.1 & 50 & 250 & 176.7 & 7195.4 \\
\hline RAND5-6 & $200 \times 200$ & 66 & 2.6 & 0.9 & 50 & 150 & 143.3 & 3057.5 \\
\hline RAND5-7 & $250 \times 250$ & 57 & 2.3 & 1.0 & 50 & 300 & 186.7 & 7402.3 \\
\hline RAND5-8 & $200 \times 250$ & 74 & 2.5 & 1.0 & 50 & 300 & 173.3 & 6160.9 \\
\hline RAND5-9 & $200 \times 250$ & 70 & 2.3 & 1.0 & 200 & 350 & 183.3 & 6781.6 \\
\hline RAND5-10 & $250 \times 150$ & 81 & 2.3 & 1.2 & 50 & 200 & 123.8 & 3809.5 \\
\hline RAND6-1 & $200 \times 250$ & 74 & 2.5 & 1.0 & 50 & 300 & 173.3 & 6160.9 \\
\hline RAND6-2 & $200 \times 200$ & 99 & 2.8 & 1.3 & 50 & 250 & 147.6 & 4994.2 \\
\hline RAND6-3 & $200 \times 250$ & 91 & 2.5 & 1.2 & 50 & 200 & 161.9 & 5342.6 \\
\hline RAND6-4 & $200 \times 250$ & 72 & 2.4 & 0.9 & 50 & 200 & 138.1 & 4854.8 \\
\hline RAND6-5 & $250 \times 150$ & 73 & 2.4 & 0.9 & 50 & 250 & 142.9 & 4947.7 \\
\hline RAND6-6 & $250 \times 250$ & 97 & 2.7 & 0.9 & 100 & 200 & 185.7 & 6132.4 \\
\hline RAND6-7 & $200 \times 200$ & 99 & 2.8 & 1.3 & 50 & 250 & 147.6 & 4994.2 \\
\hline RAND6-8 & $250 \times 200$ & 80 & 2.7 & 1.0 & 50 & 250 & 161.9 & 6806.0 \\
\hline RAND6-9 & $250 \times 200$ & 98 & 2.7 & 1.1 & 50 & 300 & 142.9 & 4703.8 \\
\hline RAND6-10 & $150 \times 250$ & 106 & 2.9 & 0.7 & 50 & 250 & 138.1 & 4854.8 \\
\hline RAND7-1 & $200 \times 200$ & 102 & 2.4 & 1.1 & 50 & 200 & 132.1 & 3675.3 \\
\hline RAND7-2 & $250 \times 250$ & 74 & 2.1 & 0.8 & 100 & 250 & 176.8 & 6633.1 \\
\hline RAND7-3 & $250 \times 250$ & 109 & 2.6 & 0.9 & 100 & 300 & 162.5 & 5022.7 \\
\hline RAND7-4 & $250 \times 200$ & 88 & 2.5 & 1.3 & 100 & 200 & 155.4 & 5152.6 \\
\hline RAND7-5 & $250 \times 250$ & 74 & 2.1 & 0.8 & 100 & 300 & 176.8 & 6633.1 \\
\hline RAND7-6 & $250 \times 250$ & 74 & 2.1 & 0.8 & 100 & 300 & 176.8 & 6633.1 \\
\hline RAND7-7 & $250 \times 250$ & 74 & 2.1 & 0.8 & 100 & 200 & 176.8 & 6633.1 \\
\hline RAND7-8 & $250 \times 250$ & 74 & 2.1 & 0.8 & 100 & 300 & 176.8 & 6633.1 \\
\hline RAND7-9 & $250 \times 250$ & 74 & 2.1 & 0.8 & 150 & 250 & 176.8 & 6633.1 \\
\hline RAND7-10 & $250 \times 250$ & 74 & 2.1 & 0.8 & 100 & 400 & 176.8 & 6633.1 \\
\hline RAND8-1 & $200 \times 250$ & 126 & 2.6 & 1.2 & 50 & 300 & 141.7 & 4436.6 \\
\hline RAND8-2 & $200 \times 250$ & 126 & 2.6 & 1.2 & 50 & 250 & 141.7 & 4436.6 \\
\hline RAND8-3 & $200 \times 250$ & 126 & 2.6 & 1.2 & 50 & 150 & 141.7 & 4436.6 \\
\hline RAND8-4 & $200 \times 250$ & 126 & 2.6 & 1.2 & 50 & 150 & 141.7 & 4436.6 \\
\hline RAND8-5 & $200 \times 250$ & 126 & 2.6 & 1.2 & 50 & 200 & 141.7 & 4436.6 \\
\hline RAND8-6 & $200 \times 250$ & 126 & 2.6 & 1.2 & 150 & 300 & 141.7 & 4436.6 \\
\hline RAND8-7 & $200 \times 250$ & 126 & 2.6 & 1.2 & 50 & 200 & 141.7 & 4436.6 \\
\hline RAND8-8 & $200 \times 250$ & 126 & 2.6 & 1.2 & 50 & 250 & 141.7 & 4436.6 \\
\hline RAND8-9 & $200 \times 250$ & 150 & 3.1 & 0.8 & 100 & 350 & 163.9 & 5438.2 \\
\hline RAND8-10 & $200 \times 250$ & 150 & 3.1 & 0.8 & 100 & 350 & 163.9 & 5438.2 \\
\hline
\end{tabular}

Note: the problem is denoted by RAND (number 1)-(number 2) where number 1 is the number of satellite depots and ranges from 4 to 7 , and number 2 is the instance sequence in a similar set. 
TABLE 2: Computational results for the 40 test problems.

\begin{tabular}{|c|c|c|c|c|c|}
\hline \multirow{2}{*}{ Problem } & \multicolumn{2}{|c|}{ CPLEX } & \multicolumn{2}{|c|}{ SA } & \multirow{2}{*}{ Gap (\%) } \\
\hline & Tractor quantity & $\begin{array}{c}\mathrm{CO}_{2} \text { emissions per } \\
\text { ton-kilometer }(\mathrm{g} / \mathrm{tm})\end{array}$ & Tractor quantity & $\begin{array}{l}\mathrm{CO}_{2} \text { emissions per } \\
\text { ton-kilometer }(\mathrm{g} / \mathrm{tm})\end{array}$ & \\
\hline RAND5-1 & 11 & 65.21 & 14 & 68.82 & 5.5 \\
\hline RAND5-2 & 11 & 61.35 & 15 & 70.91 & 15.6 \\
\hline RAND5-3 & 16 & 62.14 & 14 & 67.92 & 9.3 \\
\hline RAND5-4 & 12 & 61.73 & 16 & 68.72 & 11.3 \\
\hline RAND5-5 & 12 & 64.22 & 12 & 72.83 & 13.4 \\
\hline RAND5-6 & 16 & 62.34 & 14 & 66.77 & 7.1 \\
\hline RAND5-7 & 19 & 64.17 & 13 & 64.48 & 0.5 \\
\hline RAND5-8 & 21 & 65.78 & 17 & 66.33 & 0.8 \\
\hline RAND5-9 & 31 & 79.70 & 17 & 65.90 & 17.3 \\
\hline RAND5-10 & 17 & 62.97 & 17 & 69.81 & 10.9 \\
\hline RAND6-1 & 21 & 65.78 & 17 & 66.88 & 1.7 \\
\hline RAND6-2 & 25 & 61.72 & 19 & 62.56 & 1.4 \\
\hline RAND6-3 & 24 & 64.23 & 19 & 62.56 & 2.6 \\
\hline RAND6-4 & 16 & 63.58 & 17 & 73.91 & 16.2 \\
\hline RAND6-5 & 15 & 61.12 & 16 & 70.12 & 14.7 \\
\hline RAND6-6 & 32 & 64.21 & 20 & 61.50 & 4.2 \\
\hline RAND6-7 & 27 & 62.14 & 19 & 62.77 & 1.0 \\
\hline RAND6-8 & 23 & 63.40 & 17 & 64.60 & 1.9 \\
\hline RAND6-9 & 22 & 60.53 & 18 & 60.99 & 0.8 \\
\hline RAND6-10 & 24 & 61.95 & 21 & 64.79 & 4.6 \\
\hline RAND7-1 & 21 & 61.29 & 21 & 67.62 & 10.3 \\
\hline RAND7-2 & 21 & 64.18 & 17 & 68.61 & 6.9 \\
\hline RAND7-3 & 30 & 64.49 & 21 & 63.00 & 2.3 \\
\hline RAND7-4 & 21 & 62.56 & 21 & 73.73 & 17.9 \\
\hline RAND7-5 & 23 & 69.44 & 18 & 71.65 & 3.2 \\
\hline RAND7-6 & 22 & 67.50 & 17 & 69.99 & 3.7 \\
\hline RAND7-7 & 22 & 68.05 & 17 & 68.88 & 1.2 \\
\hline RAND7-8 & 24 & 69.44 & 17 & 69.99 & 0.8 \\
\hline RAND7-9 & 22 & 73.86 & 17 & 70.82 & 4.1 \\
\hline RAND7-10 & 20 & 68.05 & 18 & 72.75 & 6.9 \\
\hline RAND8-1 & 28 & 60.69 & 33 & 67.41 & 11.1 \\
\hline RAND8-2 & 31 & 64.14 & 27 & 69.95 & 9.1 \\
\hline RAND8-3 & 29 & 62.14 & 27 & 68.86 & 10.8 \\
\hline RAND8-4 & 29 & 62.32 & 27 & 69.95 & 12.2 \\
\hline RAND8-5 & 29 & 62.14 & 27 & 69.95 & 12.6 \\
\hline RAND8-6 & 38 & 73.76 & 26 & 70.49 & 4.4 \\
\hline RAND8-7 & 30 & 62.87 & 25 & 67.04 & 6.6 \\
\hline RAND8-8 & 30 & 63.23 & 25 & 67.04 & 6.0 \\
\hline RAND8-9 & 46 & 65.09 & 30 & 62.85 & 3.4 \\
\hline RAND8-10 & 53 & 68.83 & 32 & 65.46 & 4.9 \\
\hline
\end{tabular}

Note: with the total number of tractors (H) enumerated, the computation time for CPLEX12.4 was limited to one hour. The solutions obtained by CPLEX are not absolutely theoretically optimal ones. 
TABLE 3: The distances between any two cities $(\mathrm{km})$.

\begin{tabular}{|c|c|c|c|c|c|c|c|c|c|c|c|c|c|c|c|c|c|}
\hline & JNA & QD & $\mathrm{ZB}$ & $\mathrm{ZZH}$ & DY & YT & WF & JNI & TA & WH & $\mathrm{RZH}$ & LW & LY & $\mathrm{DZH}$ & $\mathrm{LCH}$ & $\mathrm{BZH}$ & $\mathrm{HZ}$ \\
\hline JNA & 0 & 361 & 111 & 245 & 225 & 457 & 209 & 202 & 75 & 517 & 332 & 86 & 250 & 131 & 125 & 159 & 251 \\
\hline QD & 361 & 0 & 263 & 429 & 275 & 251 & 157 & 448 & 363 & 272 & 175 & 308 & 300 & 469 & 464 & 330 & 557 \\
\hline ZB & 111 & 263 & 0 & 313 & 128 & 360 & 112 & 270 & 146 & 419 & 323 & 91 & 240 & 222 & 216 & 83 & 357 \\
\hline ZZH & 245 & 429 & 313 & 0 & 439 & 589 & 424 & 137 & 172 & 649 & 267 & 222 & 116 & 329 & 324 & 372 & 247 \\
\hline DY & 225 & 275 & 128 & 439 & 0 & 350 & 141 & 398 & 274 & 410 & 359 & 219 & 368 & 335 & 329 & 75 & 470 \\
\hline YT & 457 & 251 & 360 & 589 & 350 & 0 & 252 & 606 & 504 & 65 & 333 & 449 & 458 & 565 & 559 & 426 & 700 \\
\hline WF & 209 & 157 & 112 & 424 & 141 & 252 & 0 & 382 & 257 & 314 & 226 & 202 & 249 & 318 & 313 & 179 & 454 \\
\hline JNI & 202 & 448 & 270 & 137 & 398 & 606 & 382 & 0 & 130 & 667 & 285 & 180 & 203 & 287 & 156 & 331 & 126 \\
\hline TA & 75 & 363 & 146 & 172 & 274 & 504 & 257 & 130 & 0 & 566 & 277 & 58 & 195 & 169 & 163 & 207 & 240 \\
\hline WH & 517 & 272 & 419 & 649 & 410 & 65 & 314 & 667 & 566 & 0 & 395 & 510 & 519 & 626 & 621 & 487 & 762 \\
\hline RZH & 332 & 175 & 323 & 267 & 359 & 333 & 226 & 285 & 277 & 395 & 0 & 247 & 137 & 443 & 437 & 383 & 395 \\
\hline LW & 86 & 308 & 91 & 222 & 219 & 449 & 202 & 180 & 58 & 510 & 247 & 0 & 165 & 225 & 220 & 152 & 290 \\
\hline LY & 250 & 300 & 240 & 116 & 368 & 458 & 249 & 203 & 195 & 519 & 137 & 165 & 0 & 361 & 355 & 301 & 313 \\
\hline $\mathrm{DZH}$ & 131 & 469 & 222 & 329 & 335 & 565 & 318 & 287 & 169 & 626 & 443 & 225 & 361 & 0 & 180 & 271 & 338 \\
\hline LCH & 125 & 464 & 216 & 324 & 329 & 559 & 313 & 156 & 163 & 621 & 437 & 220 & 355 & 180 & 0 & 263 & 225 \\
\hline $\mathrm{BZH}$ & 159 & 330 & 83 & 372 & 75 & 426 & 179 & 331 & 207 & 487 & 383 & 152 & 301 & 271 & 263 & 0 & 404 \\
\hline $\mathrm{HZ}$ & 251 & 557 & 357 & 247 & 470 & 700 & 454 & 126 & 240 & 762 & 395 & 290 & 313 & 338 & 225 & 404 & 0 \\
\hline
\end{tabular}

TABLE 4: The freight flows between any two cities (unit: loaded semitrailer).

\begin{tabular}{lcccccccccccccccccc}
\hline To & JNA & QD & ZB & ZZH & DY & YT & WF & JNI & TA & WH & RZH & LW & LY & DZH & LCH & BZH & HZ \\
\hline JNA & 0 & 1 & 2 & 1 & 2 & 1 & 3 & 1 & 0 & 0 & 0 & 0 & 1 & 0 & 1 & 2 & 1 \\
QD & 1 & 0 & 6 & 0 & 4 & 7 & 18 & 0 & 1 & 3 & 3 & 1 & 2 & 1 & 1 & 1 & 0 \\
ZB & 1 & 4 & 0 & 1 & 2 & 2 & 3 & 1 & 1 & 1 & 0 & 0 & 3 & 3 & 3 & 0 & 1 \\
ZZH & 1 & 0 & 1 & 0 & 0 & 0 & 0 & 0 & 1 & 0 & 0 & 0 & 0 & 0 & 0 & 0 & 0 \\
DY & 2 & 3 & 2 & 0 & 0 & 1 & 1 & 0 & 1 & 0 & 0 & 0 & 1 & 1 & 1 & 0 & 0 \\
YT & 1 & 6 & 2 & 0 & 2 & 0 & 5 & 0 & 0 & 1 & 1 & 0 & 1 & 0 & 0 & 0 & 0 \\
WF & 3 & 15 & 3 & 0 & 1 & 4 & 0 & 1 & 2 & 1 & 1 & 1 & 2 & 1 & 1 & 4 & 0 \\
JNI & 1 & 0 & 1 & 0 & 0 & 0 & 1 & 0 & 0 & 0 & 0 & 0 & 1 & 1 & 2 & 0 & 0 \\
TA & 0 & 1 & 1 & 1 & 1 & 0 & 2 & 0 & 0 & 0 & 0 & 0 & 2 & 2 & 3 & 1 & 1 \\
WH & 0 & 2 & 1 & 0 & 1 & 1 & 1 & 0 & 0 & 0 & 0 & 0 & 0 & 0 & 0 & 0 & 0 \\
RZH & 0 & 3 & 1 & 0 & 0 & 1 & 1 & 0 & 0 & 0 & 0 & 0 & 0 & 0 & 0 & 0 & 0 \\
LW & 0 & 0 & 0 & 0 & 1 & 0 & 1 & 0 & 0 & 0 & 0 & 0 & 1 & 0 & 1 & 1 & 0 \\
LY & 1 & 2 & 3 & 0 & 1 & 1 & 2 & 1 & 2 & 0 & 0 & 1 & 0 & 0 & 1 & 1 \\
DZH & 0 & 0 & 3 & 0 & 1 & 0 & 1 & 1 & 2 & 0 & 0 & 0 & 0 & 0 & 2 & 1 \\
LCH & 1 & 1 & 4 & 0 & 1 & 0 & 1 & 2 & 3 & 0 & 0 & 1 & 0 & 2 & 0 \\
BZH & 2 & 1 & 0 & 0 & 0 & 0 & 4 & 0 & 1 & 0 & 0 & 1 & 1 & 1 & 1 \\
HZ & 1 & 0 & 1 & 0 & 0 & 0 & 0 & 0 & 1 & 0 & 0 & 0 & 0 & 0 & 1 \\
\hline
\end{tabular}

time. According to SDEXP experience, a driver's average onduty time is 8.5 hours per day. A tractor with two drivers can work consecutively for no more than 17.0 hours in a 24consecutive-hour period. The attach/detach time at satellite depots is $2 / 3$ hour, and the residence time in the central depot is 2 hours.

In the computational study, we assume any one of the 6 cities the candidate central depot city for SDEXP. There are 6 scenarios classified by the candidate central depot cities. The satisfactory solutions of the 6 scenarios are in
Table 5. The SA heuristic was run for 5 times for any scenario and the average was showed. When the depot located in a different spatial zone and having various freight flows is, respectively, regarded as the central depot, the performance of the satisfactory solution varies obviously. We use "tractor quantity," "percentage of fuel consumption for tractor running alone," and " $\mathrm{CO}_{2}$ emissions per ton-kilometer" to show the performance of the solution.

Since the loaded semitrailer needing transport and its transported distance are certain, the total ton-kilometer is 
TABLE 5: The results of the 6 scenarios of the realistic instance.

\begin{tabular}{lccccc}
\hline $\begin{array}{l}\text { The central } \\
\text { depot city }\end{array}$ & $\begin{array}{c}\text { Tractor } \\
\text { quantity }\end{array}$ & $\begin{array}{c}\text { Average number of loaded } \\
\text { semitrailer on a route }\end{array}$ & $\begin{array}{c}\text { Average distance } \\
\text { span }(\mathrm{km})\end{array}$ & $\begin{array}{c}\text { Percentage of fuel consumption } \\
\text { for tractor running alone }(\%)\end{array}$ & $\begin{array}{c}\mathrm{CO}_{2} \text { emissions per } \\
\text { ton-kilometer }(\mathrm{g} / \mathrm{tm})\end{array}$ \\
\hline JNA & 84 & 3.0 & 1067.8 & 20.2 & 72.9 \\
QD & 89 & 2.8 & 1096.6 & 24.5 & 77.1 \\
ZB & 79 & 3.2 & 1050.5 & 16.1 & 69.4 \\
WF & 74 & 3.4 & 1066.9 & 13.4 & 67.3 \\
TA & 94 & 2.7 & 1070.7 & 26.2 & 79.3 \\
LW & 89 & 2.8 & 1054.2 & 22.5 & 75.1 \\
\hline
\end{tabular}

certain. When the distance span is decided, the more the tractor number, the more the percentage of fuel consumption for tractor running alone. Less number of tractors leads to more loaded semitrailer on a route. There exists an obvious relationship between "percentage of fuel consumption for tractor running alone" and " $\mathrm{CO}_{2}$ emissions per tonkilometer." More "percentage of fuel consumption for tractor running alone" likely leads to more " $\mathrm{CO}_{2}$ emissions per tonkilometer."

Escobar et al. [44] and Hashemi et al. [45] pointed that the transportation costs are often influenced by the decision of locating a depot and vice versa. Our results showed a similar conclusion. According to the methodology and factors developed by the Intergovernmental Panel on Climate Change (IPCC), $\mathrm{CO}_{2}$ emissions are in direct proportion to fuel consumption, so $\mathrm{CO}_{2}$ emissions of the solutions can express the variable cost of transportation. The solutions for various central depot cities have different $\mathrm{CO}_{2}$ emissions per ton-kilometer. Central depot cities located near the center of the research spatial scope (e.g., WF, ZB, and JNA) have relatively good solutions. Besides, central depot cities located along Jinan-Qingdao Highway (JNA-ZB-WF-QD line) have good solutions that include more loaded semitrailer on a route and a low level of $\mathrm{CO}_{2}$ emissions per ton-kilometer. It is implied that the $\mathrm{CO}_{2}$ emissions per ton-kilometer of the solutions for different central depot cities are affected not only by central depot locations but also by transportation flows from economic relations.

There are estimation results of $\mathrm{CO}_{2}$ emissions per tonkilometer for various countries. For example, Van Ierland et al. [13] noted that the $\mathrm{CO}_{2}$ emission factor for trucks was $155 \mathrm{~g} \mathrm{CO}_{2} / \mathrm{t}-\mathrm{km}$ in The Netherlands. European Environment Agency [46] noted that the average $\mathrm{CO}_{2}$ emissions were 62 $110 \mathrm{~g} \mathrm{CO}_{2} / \mathrm{t}-\mathrm{km}$ for road transportation in the EU Member States. $\mathrm{Li}$ et al. [47] noted that the average $\mathrm{CO}_{2}$ emissions fluctuated between $100 \mathrm{~g} \mathrm{CO}_{2} / \mathrm{t}-\mathrm{km}$ and $132 \mathrm{~g} \mathrm{CO}_{2} / \mathrm{t}-\mathrm{km}$ from 1985 to 2007 in China. We have investigated some point-topoint haulages of SDEXP in 2009 and found that the $\mathrm{CO}_{2}$ emission factor ranged from $100 \mathrm{~g} \mathrm{CO}_{2} / \mathrm{t}-\mathrm{km}$ to $180 \mathrm{~g} \mathrm{CO}_{2} / \mathrm{t}-$ $\mathrm{km}$, and the average was $135 \mathrm{~g} \mathrm{CO}_{2} / \mathrm{t}-\mathrm{km}$. Our computational realistic-instance study showed that the vehicle scheduling provided by the TSRP is promising to reduce road freight transportation $\mathrm{CO}_{2}$ emissions.

The results suggested that SDEXP can locate the central depot in city WF, ZB, or JNA. About 80 tractors are needed to serve routes of around $1000 \mathrm{~km}$ distance. With the help of the TSRP satisfactory solution, SDEXP is likely to reduce around $30 \%$ of the $\mathrm{CO}_{2}$ emissions per ton-kilometer.

\section{Conclusions}

This paper discussed the tractor and semitrailer routing problem with the objective of minimizing the $\mathrm{CO}_{2}$ emissions per ton-kilometer, which are promising with applications in multilevel freight distribution systems and full truckload. An exact formulation was presented. The SA heuristic was put forward to solve this problem of a realistic size. The SA heuristics algorithm was tested on different types of problems. The experimental results showed that the proposed heuristics provide satisfactory-quality solutions in a reasonable computing time. The impact of central depot locations and freight flow distributions on the solution quality is also explored. In conclusion, the proposed algorithms can provide robust solutions.

For future research, it would be interesting to test the effectiveness and efficiency of the proposed TSRP model and its solution approach on large-scale instances. Some efficient heuristics for the TSRP may also be proposed. Besides, attention can be focused on the extension of the TSRP, for example, TSRP with time windows and TSRP with vehicle routing of other levels of freight distribution system.

\section{Acknowledgment}

This work was supported by research Grant from the National Natural Science Foundation of China (nos. 71202016 and 71071007). This support is gratefully acknowledged.

\section{References}

[1] D. Y. Lin and K. H. Ng, "The impact of collaborative backhaul routing on carbon reduction in the freight industry," Transportation Research Part D, vol. 17, pp. 626-628, 2012.

[2] Y. Kuo, "Using simulated annealing to minimize fuel consumption for the time-dependent vehicle routing problem," Computers and Industrial Engineering, vol. 59, no. 1, pp. 157-165, 2010.

[3] I. Kara, B. Y. Kara, and M. K. Yetis, "Energy minimizing vehicle routing problem," in Combinatorial Optimization and Applications, vol. 4616 of Lecture Notes in Computer Science, pp. 62-71, Springer, Berlin, Germany, 2007. 
[4] Y. Xiao, Q. Zhao, I. Kaku, and Y. Xu, "Development of a fuel consumption optimization model for the capacitated vehicle routing problem," Computers \& Operations Research, vol. 39, no. 7, pp. 1419-1431, 2012.

[5] Y. J. Kwon, Y. J. Choi, and D. H. Lee, "Heterogeneous fixed fleet vehicle routing considering carbon emission," Transportation Research Part D, vol. 23, pp. 81-89, 2013.

[6] L. Pradenas, B. Oportus, and V. Parada, "Mitigation of greenhouse gas emissions in vehicle routing problems with backhauling," Expert Systems with Applications, vol. 40, pp. 2985-2991, 2013.

[7] M. Drexl, "Applications of the vehicle routing problem with trailers and transshipments," European Journal of Operational Research, vol. 227, pp. 275-283, 2013.

[8] R. S. de Camargo, G. de Miranda, and A. Løkketangen, "A new formulation and an exact approach for the many-to-many hub location-routing problem," Applied Mathematical Modelling, vol. 37, no. 12-13, pp. 7465-7480, 2013.

[9] V. C. Hemmelmayr, J.-F. Cordeau, and T. G. Crainic, "An adaptive large neighborhood search heuristic for two-echelon vehicle routing problems arising in city logistics," Computers \& Operations Research, vol. 39, no. 12, pp. 3215-3228, 2012.

[10] P. C. Pop, I. Kara, and A. Horvat Marc, "New mathematical models of the generalized vehicle routing problem and extensions," Applied Mathematical Modelling, vol. 36, no. 1, pp. 97-107, 2012.

[11] C. Contardo, V. Hemmelmayr, and T. G. Crainic, "Lower and upper bounds for the two-echelon capacitated location-routing problem," Computers \& Operations Research, vol. 39, no. 12, pp. 3185-3199, 2012.

[12] H. Q. Li and Y. Lu, "Tractor and semi-trailer transportation's effect on the reduction of $\mathrm{CO}_{2}$ emission in China," in Systems Science and Transportation Development, B. H. Mao, S. J. Yang, and L. L. Yang, Eds., pp. 232-237, The Institution of Engineering and Technology, Beijing, China, 2011.

[13] E. Van Ierland, C. Graveland, and R. Huiberts, "An environmental economic analysis of the new rail link to European main port Rotterdam," Transportation Research Part D, vol. 5, no. 3, pp. 197-209, 2000.

[14] J. G. Villegas, C. Prins, C. Prodhon, A. L. Medaglia, and N. Velasco, "A matheuristic for the truck and trailer routing problem," European Journal of Operational Research, vol. 230, no. 2, pp. 231-244, 2013.

[15] F. Semet and E. Taillard, "Solving real-life vehicle routing problems efficiently using tabu search," Annals of Operations Research, vol. 41, no. 4, pp. 469-488, 1993.

[16] M. Caramia and F. Guerriero, "A milk collection problem with incompatibility constraints," Interfaces, vol. 40, no. 2, pp. 130$143,2010$.

[17] J. C. Gerdessen, "Vehicle routing problem with trailers," European Journal of Operational Research, vol. 93, no. 1, pp. 135-147, 1996.

[18] I.-M. Chao, "A tabu search method for the truck and trailer routing problem," Computers and Operations Research, vol. 29, no. 1, pp. 33-51, 2002.

[19] S. Scheuerer, "A tabu search heuristic for the truck and trailer routing problem," Computers and Operations Research, vol. 33, no. 4, pp. 894-909, 2006.

[20] K. C. Tan, Y. H. Chew, and L. H. Lee, "A hybrid multi-objective evolutionary algorithm for solving truck and trailer vehicle routing problems," European Journal of Operational Research, vol. 172, no. 3, pp. 855-885, 2006.
[21] S.-W. Lin, V. F. Yu, and S.-Y. Chou, "Solving the truck and trailer routing problem based on a simulated annealing heuristic," Computers and Operations Research, vol. 36, no. 5, pp. 1683$1692,2009$.

[22] J. G. Villegas, C. Prins, C. Prodhon, A. L. Medaglia, and N. Velasco, "A GRASP with evolutionary path relinking for the truck and trailer routing problem," Computers and Operations Research, vol. 38, no. 9, pp. 1319-1334, 2011.

[23] J. G. Villegas, C. Prins, C. Prodhon, A. L. Medaglia, and N. Velasco, "GRASP/VND and multi-start evolutionary local search for the single truck and trailer routing problem with satellite depots," Engineering Applications of Artificial Intelligence, vol. 23, no. 5, pp. 780-794, 2010.

[24] S.-W. Lin, V. F. Yu, and S.-Y. Chou, "A note on the truck and trailer routing problem," Expert Systems with Applications, vol. 37, no. 1, pp. 899-903, 2010.

[25] S.-W. Lin, V. F. Yu, and C.-C. Lu, "A simulated annealing heuristic for the truck and trailer routing problem with time windows," Expert Systems with Applications, vol. 38, no. 12, pp. 15244-15252, 2011.

[26] U. Derigs, M. Pullmann, and U. Vogel, "Truck and trailer routing-problems, heuristics and computational experience," Computers \& Operations Research, vol. 40, pp. 536-546, 2013.

[27] V. Pureza, R. Morabito, and M. Reimann, "Vehicle routing with multiple deliverymen: modeling and heuristic approaches for the VRPTW,' European Journal of Operational Research, vol. 218, no. 3, pp. 636-647, 2012.

[28] L. Bodin, A. Mingozzi, R. Baldacci, and M. Ball, "Rollon-Rolloff vehicle routing problem," Transportation Science, vol. 34, no. 3, pp. 271-288, 2000.

[29] J. Wy and B. I. Kim, "A hybrid metaheuristic approach for the rollon-rolloff vehicle routing problem," Computers \& Operations Research, vol. 40, pp. 1947-1952, 2013.

[30] U. Derigs, M. Pullmann, and U. Vogel, "A short note on applying a simple LS/LNS-based metaheuristic to the rollon-rolloff vehicle routing problem," Computers \& Operations Research, vol. 40, pp. 867-872, 2013.

[31] J. Wy, B. I. Kim, and S. Kim, "The rollon-rolloff waste collection vehicle routing problem with time windows," European Journal of Operational Research, vol. 224, pp. 466-476, 2013.

[32] R. Baldacci, L. Bodin, and A. Mingozzi, “The multiple disposal facilities and multiple inventory locations rollon-rolloff vehicle routing problem," Computers and Operations Research, vol. 33, no. 9, pp. 2667-2702, 2006.

[33] R. W. Hall and V. C. Sabnani, "Control of vehicle dispatching on a cyclic route serving trucking terminals," Transportation Research Part A, vol. 36, no. 3, pp. 257-276, 2002.

[34] P. Francis, G. Zhang, and K. Smilowitz, "Improved modeling and solution methods for the multi-resource routing problem," European Journal of Operational Research, vol. 180, no. 3, pp. 1045-1059, 2007.

[35] Y.-R. Cheng, B. Liang, and M.-H. Zhou, "Optimization for vehicle scheduling in iron and steel works based on semitrailer swap transport," Journal of Central South University of Technology, vol. 17, no. 4, pp. 873-879, 2010.

[36] U. Derigs, R. Kurowsky, and U. Vogel, "Solving a real-world vehicle routing problem with multiple use of tractors and trailers and EU-regulations for drivers arising in air cargo road feeder services," European Journal of Operational Research, vol. 213, no. 1, pp. 309-319, 2011. 
[37] H. Li, Y. Lu, J. Zhang, and T. Wang, "Solving the tractor and semi-trailer routing problem based on a heuristic approach," Mathematical Problems in Engineering, vol. 2012, Article ID 182584, 12 pages, 2012.

[38] S. Almoustafa, S. Hanafi, and N. Mladenović, "New exact method for large asymmetric distance-constrained vehicle routing problem," European Journal of Operational Research, vol. 226, no. 3, pp. 386-394, 2013.

[39] R. Baños, J. Ortega, C. Gil, A. Fernández, and F. Toro, "A Simulated Annealing-based parallel multi-objective approach to vehicle routing problems with time windows," Expert Systems with Applications, vol. 40, pp. 1696-1707, 2013.

[40] O. Bräysy and M. Gendreau, "Vehicle routing problem with time windows, Part I: route construction and local search algorithms," Transportation Science, vol. 39, no. 1, pp. 104-118, 2005.

[41] A. N. Letchford and J.-J. Salazar-González, "Projection results for vehicle routing," Mathematical Programming, vol. 105, no. 23, pp. 251-274, 2006.

[42] L. C. Coelho, J.-F. Cordeau, and G. Laporte, "Consistency in multi-vehicle inventory-routing," Transportation Research Part C, vol. 24, pp. 270-287, 2012.

[43] R. Baños, J. Ortega, C. Gil, A. L. Márquez, and F. Toro, "A hybrid meta-heuristic for multi-objective vehicle routing problems with time windows," Computers \& Industrial Engineering, vol. 65, pp. 286-296, 2013.

[44] J. W. Escobar, R. Linfati, and P. Toth, "A two-phase hybrid heuristic algorithm for the capacitated location-routing problem," Computers \& Operations Research, vol. 40, no. 1, pp. 70-79, 2013.

[45] S. H. Hashemi Doulabi and A. Seifi, "Lower and upper bounds for location-arc routing problems with vehicle capacity constraints," European Journal of Operational Research, vol. 224, no. 1, pp. 189-208, 2013.

[46] European Environment Agency, Transport at a CrossroadsTERM, 2008: Indicators Tracking Transport and Environment in the European Union, Office for Official Publications of the European Communities, Esch-sur-Alzette, Luxembourg, 2009.

[47] H. Q. Li, Y. Lu, J. Zhang, and T. Y. Wang, "Trends in road freight transportation carbon dioxide emissions and policies in China," Energy Policy, vol. 57, pp. 99-106, 2013. 


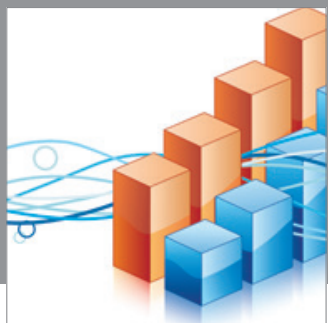

Advances in

Operations Research

mansans

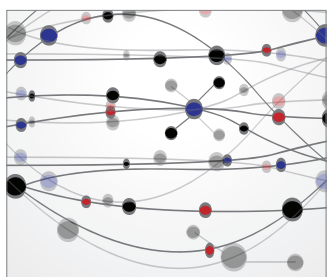

The Scientific World Journal
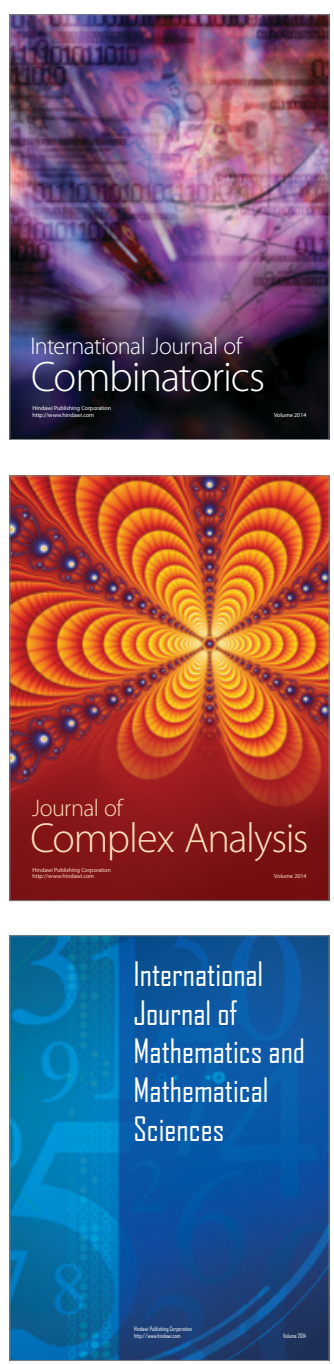
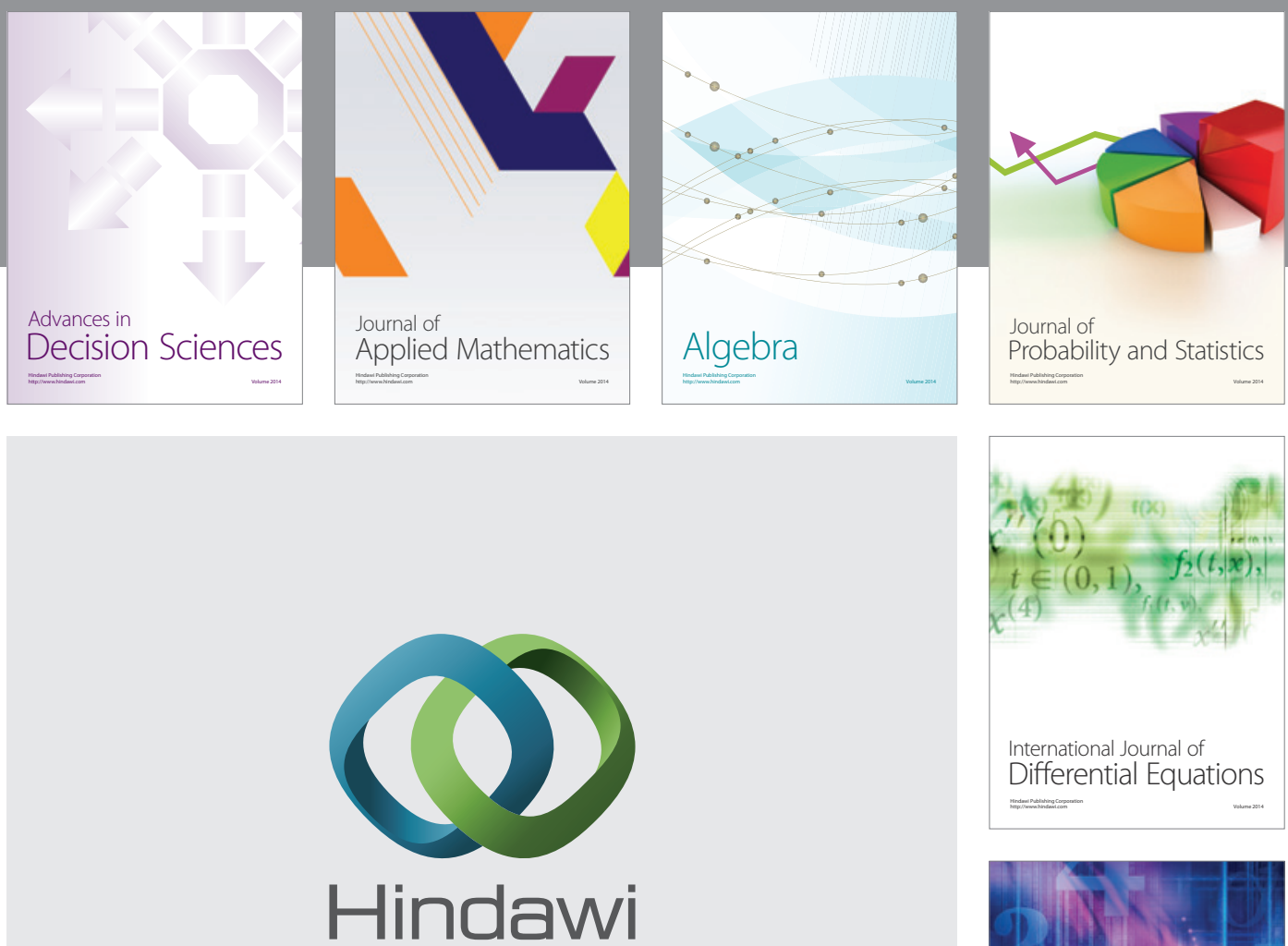

Submit your manuscripts at http://www.hindawi.com
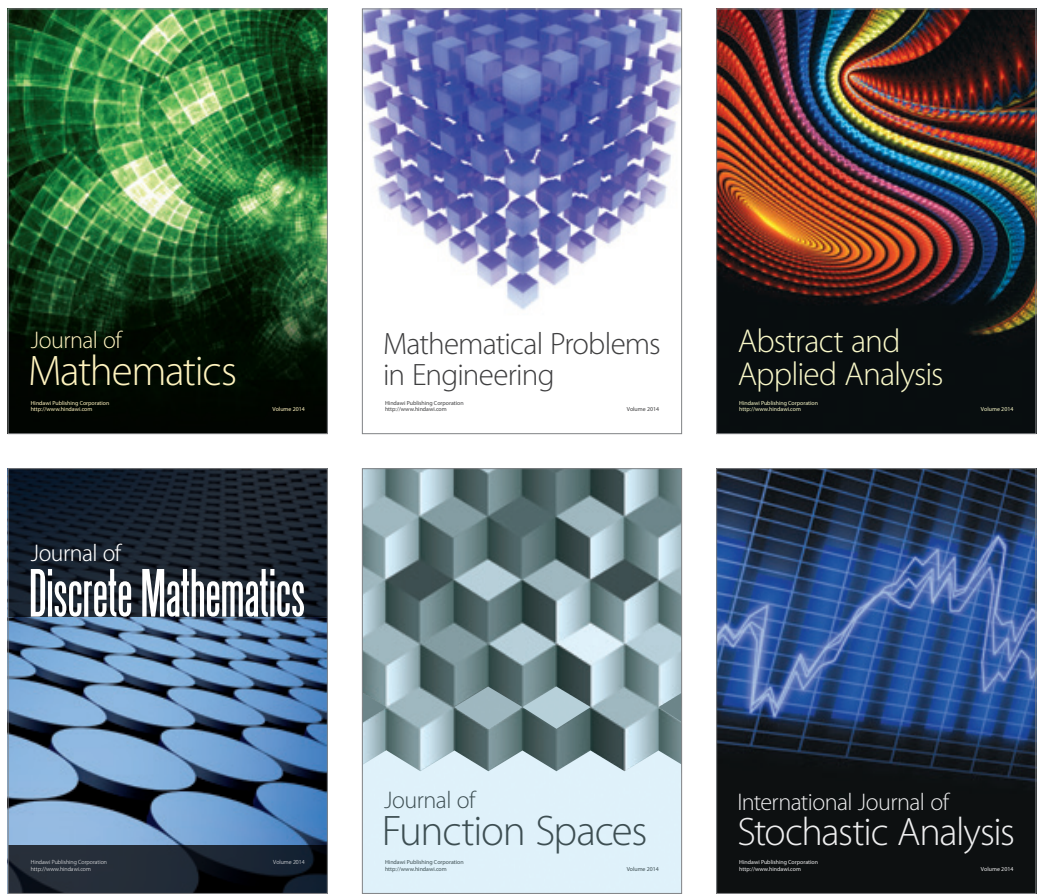

Journal of

Function Spaces

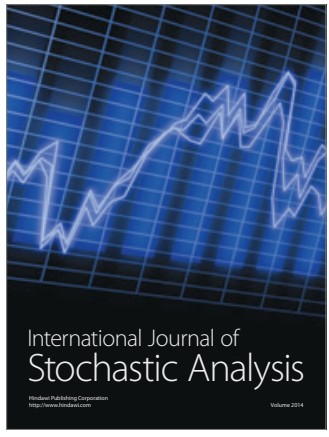

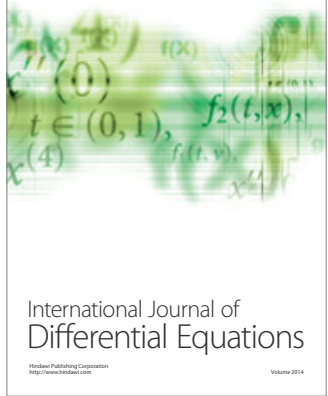
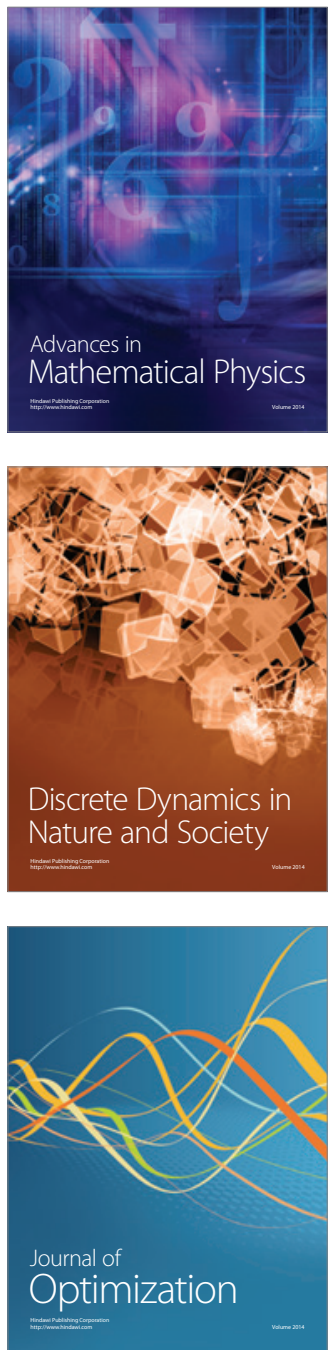